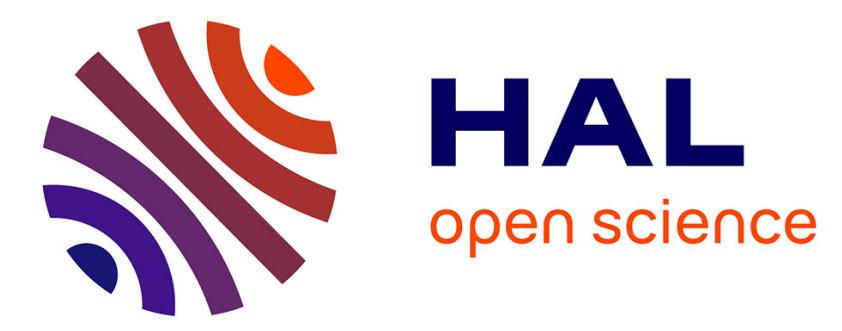

\title{
An optical instrument for the submillimeter spectroscopy of the volatile metabolome
}

Francois Bondu, Goulc'Hen Loas, Ludovic Frein, Cyril Hamel, Anthony Carré, Guillaume Ducournau, Jean-Francois Lampin, Virginie Daburon, Francoise Binet

\section{To cite this version:}

Francois Bondu, Goulc'Hen Loas, Ludovic Frein, Cyril Hamel, Anthony Carré, et al.. An optical instrument for the submillimeter spectroscopy of the volatile metabolome. 2019 44th International Conference on Infrared, Millimeter, and Terahertz Waves (IRMMW-THz), Sep 2019, Paris, France. pp.19149312. hal-02292414

\section{HAL Id: hal-02292414 https://hal.science/hal-02292414}

Submitted on 19 Sep 2019

HAL is a multi-disciplinary open access archive for the deposit and dissemination of scientific research documents, whether they are published or not. The documents may come from teaching and research institutions in France or abroad, or from public or private research centers.
L'archive ouverte pluridisciplinaire HAL, est destinée au dépôt et à la diffusion de documents scientifiques de niveau recherche, publiés ou non, émanant des établissements d'enseignement et de recherche français ou étrangers, des laboratoires publics ou privés. 


\title{
An optical instrument for the submillimeter spectroscopy of the volatile metabolome
}

\author{
François Bondu ${ }^{1}$, Goulc'hen Loas ${ }^{1}$, Ludovic Frein ${ }^{1}$, Cyril Hamel ${ }^{1}$, Anthony Carré ${ }^{1}$, Guillaume \\ Ducournau $^{2}$, Jean-François Lampin ${ }^{2}$, Virginie Daburon ${ }^{3}$, Françoise Binet ${ }^{3}$ \\ ${ }^{1}$ Institut FOTON - UMR CNRS 6082, Univ Rennes, CNRS, , Rennes, France \\ ${ }^{2}$ IEMN - UMR CNRS 8520, Université de Lille 1, Villeneuve d'Ascq, France \\ ${ }^{3}$ Ecobio - UMR 6553, Univ Rennes, CNRS, France
}

\begin{abstract}
We are designing and realizing an instrument for the spectroscopy of the volatile metabolome of the soil microorganisms. The use of optical telecommunication elements makes it possible to realize a compact source with a wide range of accessible frequencies $\left(100 \mathrm{GHz}-1 \mathrm{THz}\right.$ range; $\left.3-33 \mathrm{~cm}^{-}{ }^{1}\right)$ with an accuracy of $10^{5} \mathrm{~Hz}\left(3.10^{-6} \mathrm{~cm}^{-}\right)$, as well as a low bandwidth detection system. The instrument will discriminate among complex polar molecules. We report on the preliminary performances of parts of the source system.
\end{abstract}

\section{INTRODUCTION}

$\mathrm{T}$ ACKLING the complex ecological situations of living bodies adequate tools. This complexity has multiple aspects. No vegetal or animal living organism is on its own: it always needs the contribution of diverse communities of microorganisms. Most species of microorganisms can not be grown alone in Petri dishes, making it hard to pinpoint them. Scale laws in ecology suggest that the ratio of known species of microorganisms to unknown ones might be a ratio of the order of $10^{-5}$ [1]. There is a difficulty to match the results on microorganism population presence given with the genomics techniques compared to the techniques that observe living material. The soil itself is a large reservoir of microorganisms, with a number of $10^{6}$ to $10^{9}$ per gram. How the bacterial diversity and function in soil are linked to biotic control is an open issue [2]. The use of new instruments targeting the volatile metabolomes of microorganisms may contribute to the global comprehension of the possible equilibrium or dynamical evolution of complex communities, a goal that looks way ahead today.

The submillimeter spectroscopy has been historically developed for astronomy purposes [3], leading to the identification of molecules as complex as alanine in the inter stellar medium. This technique has not been used, up to now, for the analysis of the metabolism of microorganisms. One possible reason might be the complexity of operation and space requirements of the existing apparatus. Even in the lab, the change from one frequency band to another one, with various multipliers, amplifiers, connectors, waveguides, is tedious. However, the submillimeter spectroscopy would present advantageous characters. Contrary to the chromatography - mass spectrometry instruments and similar apparatus, it does not require heat or high pressures, thus promises a better integrity of the complex biological molecules. Even more, at low pressure and at room temperature, the absorption linewidths reduce to the range of some hundreds of $\mathrm{kHz}$, thus simultaneously making a clear discrimination between molecules types and conformations and improving the signal to noise ratio.

The analysis of the metabolism of a variety of microorganisms requires sensitivity to a wide range of organic molecules. The access to a wide range of attainable frequencies seems thus to be a desirable target: for one given organic molecule, public tables (HITRAN, JPL, CDMS) indicate that the absorption peak that gives the maximum sensitivity can not be constrained to a restricted frequency band. For that prospect, the techniques based on optical photomixing [4] seem to be more promising than the techniques based on up-conversion of microwave signals [5].

We aim to build a compact instrument based on optical elements designed for the optical telecommunications. A challenge with optical techniques is that the accessible range for the frequency of a laser is often a compromise between the linewidth and a robust and repeatable operation. We demonstrate here that these key elements are simultaneously under control, still with simple and compact elements.

\section{RESULTS}

The submillimeter wave synthesizer source is based on three commercial fibered distributed feedback laser diodes (DFB) at a wavelength of $1.5 \mu \mathrm{m}$, cf. figure 1 . The frequency difference of lasers 1 and 2 is adjustable between DC and $753 \mathrm{GHz}$ with constant laser output powers, with the change of the temperature of the free-running DFB chips. The laser lines are locked to two resonances using the Pound-DreverHall technique [6], with 10's of MHz bandwidth home-made electronics. The frequency difference is then a multiple of 1 $\mathrm{GHz}$, the free spectral range of the commercial optical resonator. The frequency difference of lasers 2 and 3 can be swept continuously in a $5-10 \mathrm{GHz}$ range, when this difference is controlled with a phase locked loop. Ultimately, the submillimeter synthesizer frequency will be the difference between lasers 1 and 3, continuously tunable by contiguous segments between DC and 763 GHz. A "UTC photodiode" and associated antenna, designed and realized for the project, have a bandwidth of several hundreds of $\mathrm{GHz}$.

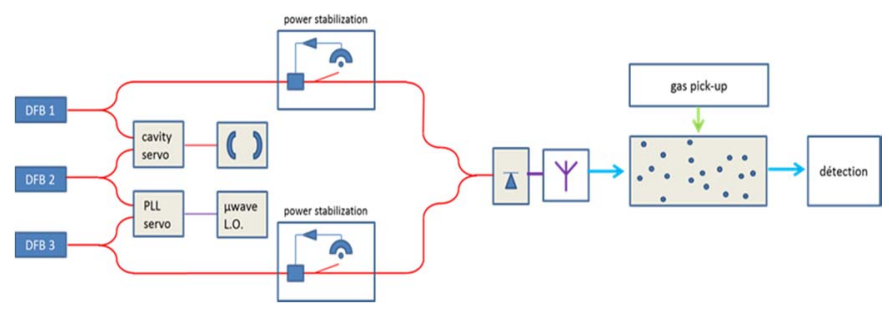

Fig. 1. Principle of the submillimeter spectroscopy instrument. On the left side, the submillimeter wave synthesizer, based on commercial telecommunication optical elements, at a wavelength of $1.5 \mu \mathrm{m}$. A dedicated UTC photodiode and antenna convert the optical radiation into a submillimeter wave in free space. 
Up to now, we have demonstrated experimentally the locking loops between laser 1 and 2 and between laser 2 and 3 separately. Figure 2 shows the performance of the phase noise of the beat notes that are measured by photomixers. The phase noise will be therefore negligible in the final system, as the linewidth of the synthesizer line is of the order of a few 10 's of $\mathrm{Hz}$.

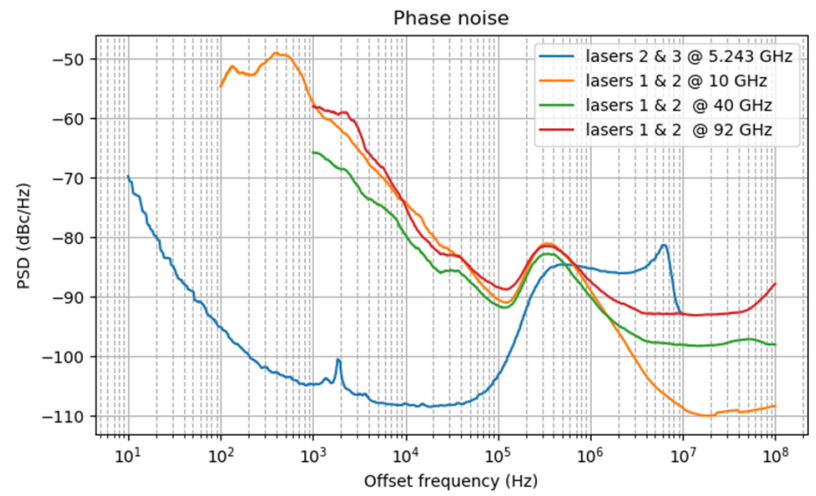

Fig. 2. Performance of the phase noise of two subsets of the frequency synthesizer source.

The required accuracy, for spectroscopy, is of the order of $10 \mathrm{kHz}$ for the radiated submillimeter wave. It seems to be at reach. The commercial optical resonator has a $1.6 \mathrm{GHz} / \mathrm{K}$ sensitivity for one optical carrier. Temperature stabilization at $1 / 10^{\text {th }}$ of a degree will be enough to disambiguate the interrogated resonance. The beat note accuracy at the $10 \mathrm{kHz}$ range should be attained with a temperature control of the cavity at a few $\mathrm{mK}$ level.

\section{NEXT STEPS}

We are now aiming at showing the performances of the full optical submillimeter synthesizer, and then at the detection system.

\section{REFERENCES}

[1] K. J. Locey et J. T. Lennon, « Scaling laws predict global microbial diversity », Proc. Natl. Acad. Sci., vol. 113, nº 21, p. 5970 5975, mai 2016.

[2] C. Monard, P. Vandenkoornhuyse, B. Le Bot, et F. Binet, « Relationship between bacterial diversity and function under biotic control: the soil pesticide degraders as a case study ", ISME J., vol. $5, \mathrm{n}^{\circ} 6$, p. 1048 1056, juin 2011.

[3] F. C. De Lucia, «The submillimeter: A spectroscopist's view », J. Mol. Spectrosc., vol. 261, $\mathrm{n}^{\mathrm{o}}$ 1, p. 1 17, mai 2010.

[4] F. Hindle et al., "Widely tunable THz synthesizer », Appl. Phys. B, vol. 104, nº 4, p. 763, août 2011.

[5] C. F. Neese, I. R. Medvedev, G. M. Plummer, A. J. Frank, C. D. Ball, et F. C. D. Lucia, « Compact Submillimeter/Terahertz Gas Sensor With Efficient Gas Collection, Preconcentration, and ppt Sensitivity », IEEE Sens. J., vol. 12, nº 8, p. 2565 2574, août 2012.

[6] A. Hallal, S. Bouhier, et F. Bondu, « Synthesis of a 30-Hz Linewidth Wave Tunable Over $500 \mathrm{GHz}$ », IEEE Trans. Microw. Theory Tech., vol. $65, \mathrm{n}^{\circ}$ 4, p. 1367 1371, avr. 2017. 